\title{
Book-Smart, Not Street-Smart: Blockchain-Based Smart Contracts and The Social Workings of Law
}

\author{
KAREN E. C. LEVY \\ CORNELL UNIVERSITY
}

\begin{abstract}
This paper critiques blockchain-based "smart contracts," which aim to automatically and securely execute obligations without reliance on a centralized enforcement authority. Though smart contracts do have some features that might serve the goals of social justice and fairness, I suggest that they are based on a thin conception of what law does, and how it does it. Smart contracts focus on the technical form of contract to the exclusion of the social contexts within which contracts operate, and the complex ways in which people use them. In the real world, contractual obligations are enforced through all kinds of social mechanisms other than formal adjudication-and contracts serve many functions that are not explicitly legal in nature, or even designed to be formally enforced. I describe three categories of contracting practices in which people engage (the inclusion of facially unenforceable terms, the inclusion of purposefully underspecified terms, and willful nonenforcement of enforceable terms) to illustrate how contracts actually "work." The technology of smart contracts neglects the fact that people use contracts as social resources to manage their relations. The inflexibility that they introduce, by design, might short-circuit a number of social uses to which law is routinely put. Therefore, I suggest that attention to the social and relational contexts of contracting are essential considerations for the discussion, development, and deployment of smart contracts.
\end{abstract}

\section{Keywords}

law; contracts; blockchain; sociolegal studies

\section{Introduction}

There has lately been much excitement about blockchain technology, and one of the chief avenues of optimism concerns its application to so-called "smart contracts." Smart contracts are agreements that utilize the blockchain-a digital ledger, distributed across a network, that securely records transactions between parties_to automatically and securely execute obligations

${ }^{1}$ Karen E. C. Levy, Email: karen.levy@cornell.edu

Copyright (C) 2017 (Karen E. C. Levy). Licensed under the Creative Commons Attribution Non-commercial No Derivatives (by-nc-nd). Available at estsjournal.org. 
when certain conditions are met; for example, a smart contract might automatically transfer ownership of an item when it is fully paid for, upon the passage of a set period of time, or upon the meeting of any other predetermined condition that can be instantiated in computer code. Because they are based on code, smart contracts can be immediately and automatically effectuated, without reliance on manual transfer, or the intervention of institutions like courts. Smart contracts have recently been heralded as "transform[ing] how the economy works" (Economist 2015), as "cryptocurrency's killer app" (Cassano 2014), as "[t]he technology most likely to change the next decade of business" (Tapscott and Tapscott 2016), and-most notably, for our purposes-"a new kind of law" that can be "perfectly observed and enforced," doing away with problematic ambiguity and expensive enforcement (EtherScripter blog, n.d.).

Like other blockchain-based technologies, the smart contract is designed to function without reliance on a centralized authority. In financial applications of blockchain technology (like cryptocurrency), the institution obviated is the system of state-issued currency and centralized banking infrastructures. For smart contracts, the authority to be avoided is the legal institution. Smart contracts are designed to self-enforce, automatically, without recourse to courts. In this sense, the smart contract can be understood alongside a number of other emergent technologies that aim to automate the enforcement of law (what Wright and de Filippi (2015) term lex cryptographia) - a vein that, read broadly, includes such seemingly disparate tools as digital rights management systems and traffic ticketing cameras. These systems are frequently received with much fanfare by policymakers, and heralded as a way to make the application of legal rules and agreements more consistent and efficient.

Though smart contracts may serve these goals in some contexts, I suggest that we should temper our enthusiasm about the transformation of modern contracting practice. This is because smart contract boosters tend to understand contracts chiefly as technical artifacts, rather than as social resources. Under this view, contractual agreements are bare financial transactions that can, and should, be optimized through code; term ambiguity and enforcement costs are understood as inefficiencies that plague the system of exchange. Understanding contracting practices within their broader social and relational contexts, by contrast, reveals that contracts are in fact much more than this: they "work" in a multitude of ways and accomplish a multitude of aims that are unaccounted for by the smart contract framework.

\section{Blockchain-based Contracts and the Promise of Code-based Enforcement}

What makes a smart contract "smart"? The underlying technology enabling smart contracts is the blockchain. Simply put, the blockchain is a database that is distributed across multiple computers. When transactions occur, records of them are aggregated into blocks of code that are appended onto the chain (the ledger of transactions). The chief benefit of this structure-which is public, and which uses sophisticated cryptography to ensure the security and trustworthiness of the record-is that it removes the need for a centralized authority to facilitate or mediate the transaction in any way. No bank has a role in setting rates or transferring funds; the security and distribution of the system stands in for this sort of external intermediary control. 
Smart contracts are, to many, the most promising application of blockchain infrastructure. The core idea is this: contracting parties agree to a set of terms that are instantiated in computer code (and which, therefore, can include any conditions which are legible to computers). When those conditions are met, transfers can be made automatically. Some of the real power of this model comes from the increasing digital interconnection of "smart" devices-imagine, for example, that a smart lock on your home could effectuate a short-term rental agreement (and then automatically lock the tenant out at the end of the lease term), or that payment for goods would transfer immediately upon arrival of those goods at a particular warehouse within a given timeframe, detectable by location-tracking technologies. In a sense, smart contracts aim to collapse contract formation and enforcement into a single instrument.

This stands in contrast to the way traditional contracts are enforced. Typically, contract terms are written and acceded to, and then-if need be-enforced, in distinct phases: if a contract is breached, the wronged party must take action to recognize and document a harm, establish the other party's responsibility for the harm, (perhaps) initiate a legal proceeding through which to establish the breach, and ensure that any damages are paid to make her "whole" again (that is, to bring her into the financial position she would have been in had the contract been fulfilled). Importantly, the enforcement phase formally depends on centralized institutions-courts-to intermediate disputes, and on a plaintiff taking affirmative steps that require access to multiple kinds of resources, including knowledge, money, and time (Felstiner et al. 1980). In short, traditional contract enforcement is messy and resource-intensive-and it is this perceived inefficiency that motivates much of the excitement about smart contracts.

To be sure, some of this enthusiasm is well placed. There are good reasons to avoid reliance on centralized authorities for governance: such an authority may be corrupt, or be subject to political forces beyond the control of the contracting parties; it may impose undue delay or bureaucratic inefficiency in resolving a conflict; it may fail altogether. And goals of social justice, equality, and fair outcomes may be served by decentralization, as well. A self-executing agreement could, in theory, obviate some of the institutional barriers that keep poor people from being able to make property claims (Casey 2016). It is widely acknowledged that well-resourced institutional players consistently obtain better outcomes in court than smaller players do, often as a result of facially neutral procedural rules and institutional structures (Galanter 1974); access to courts in the first place is quite often precluded by socioeconomic barriers. By distributing enforcement outside the centralized court system, smart contracts might, in some contexts, be seen as removing some of the barriers that keep the relatively disadvantaged from attaining their legal due.

However, scholars have raised salient critiques of the idea that smart contracts might transform the current legal regime around contractual enforcement (that is, of legal-institutionbacked "dumb" contracts). Notably, James Grimmelmann and Arvind Narayanan (2016) suggest that blockchain boosterism might be tempered with fuller consideration of the human side of business dealings. What if you lose your blockchain private key (a secret code which authenticates your ownership of resources on the blockchain) in a fire? What if you buy a defective product, and need to show your ownership to invoke state consumer protection? These 
sorts of inevitable "hiccups" are poor fits for blockchain-based enforcement, without the attendant state institutions that step in in cases of exception. Put another way, self-executing technologies like these focus on preventive security measures, ex ante, at the expense of corrective ones, ex post (Narayanan 2015). But in practice, security is fundamentally sociotechnical: it involves the confluence of both human/institutional measures and technological ones. As Grimmelmann and Narayanan illustrate, technological enforcement mechanisms (car locks, for instance) don't substitute for police or courts: a smart car lock can't prosecute someone who damaged your car. Rather, technological security solutions might work alongside state institutions, but we ought not rely on them to "solve" security on their own.

In addition, there are a number of questions about how smart contracts will deal technically with issues that are fundamental to contract law, but which are difficult to instantiate in code: issues dealing with temporality (such as mutual mistake in setting forth contract terms, or recission), or standards that apply to contracts and contractors across the board, even if not represented on the fact of the document (such as the duty of good faith). These issues represent important challenges to the smart contract framework, and there are some extant efforts to address them both technically and legally (Scholz forthcoming; Raskin forthcoming; Wright and De Filippi 2015). But I contrast my present inquiry from these concerns, which have largely to do with translation and implementation of existing legal standards to a new technological form. I also bracket from my analysis critiques of the fundamental viability of blockchain infrastructure. This critique was raised most notably in the wake of the theft of millions of dollars' worth of cryptocurrency on the Ethereum network, and the subsequent "hard fork" of the code that resulted (that is, a retrospective modification to the code governing the blockchain), believed by some to indicate the fundamental nonviability of the model (Peck 2016; Economist 2016).

My aim here is to raise a separate critique of smart contracts-one premised on the latent social functions of contracting. Just as (as Grimmelmann and Narayanan posit) the security of property depends on both technological artifacts and human institutions in the real world, so do contracts depend on both the technology of the contract-its form and provisions-and the social (human) behaviors that surround, support, and sometimes subvert contracting. This critique stands on the shoulders of fundamental work in science and technology studies that calls for attention to the social construction and effects of legal and financial instruments (e.g. Mackenzie 2008, Riles 2011, Maurer et al. 2013), as well as work in legal studies (e.g. Macneil 1978, Rose 1988) that brings a similar lens to bear on the workings of law more generally. Smart contract technology, I suggest, depends on a thin conceptualization of what law does, and how it does itby focusing on the technical form of contract, to the exclusion of the social contexts within which contracts operate, and the complex ways in which people use them.

\section{How Does Law Work?}

Law, it turns out, works through all kinds of avenues other than formal adjudication. Contracting, in particular, is a deeply social practice in which parties engage for all sorts of 
purposes, and the effects of contract negotiation reverberate outside of the "four corners" ${ }_{2}$ of a formal agreement, in both time and space. In legal studies, the legal realist perspective has long focused on how law unfolds in in vivo practice, and emphasized that these practices may diverge significantly from "on the books" codes and agreements (Mertz 1999, Macneil 1978). Significantly, this perspective suggests that parties engage with legal instruments and negotiations in order to achieve myriad socially productive aims-including many that may not be apparent from the face of an agreement. The social context of law as lived is key for understanding what law is "doing" in any particular situation. This is particularly acute in the private law context (contracting) in which parties have some latitude—at least theoretically—as to whether they engage in negotiation, and on what terms.

Among the most interesting manifestations of this is that people use legal instruments to negotiate their social and organizational lives in ways that are both complex and counterintuitive. In sum, contractual obligations are enforced through all kinds of social mechanisms other than the legal system proper; concomitantly, contracts serve many functions that are not explicitly legal in nature, or even designed to be formally enforced. This insight is important for understanding the real-life effects of automated contracts.

In what follows, I describe three contracting practices in which people engage to manage their relations. I suggest that each of these practices, while serving important social aims, are uncontemplated by the automated enforcement framework underlying so-called "smart" contracts. The practices I describe (summarized in the table below) are by no means an exhaustive list, but serve to illustrate how contracting practices operate in the wild-in ways that belie smart contracts' assumptions about how contracts "work."

\begin{tabular}{|l|l|}
\hline Contracting Practice & Social Aim \\
\hline Writing or acceding to unenforceable terms & $\begin{array}{l}\text { Set expectations for future behavior, including } \\
\text { behavior outside the formal purview of the contract }\end{array}$ \\
\hline Writing or acceding to purposefully vague terms & Facilitate stable and flexible long-term relations \\
\hline Willful nonenforcement of enforceable terms & $\begin{array}{l}\text { Provide a strategic resource for operating "in the } \\
\text { shadow of the law" }\end{array}$ \\
\hline
\end{tabular}

2 This term refers to the well-known rule in American law in which courts, in interpreting a contract will (typically) only consider the contract on its face-or within the "four corners" of the piece of paper on which it is written-in interpreting what obligations it imposes; in other words, courts will typically refrain from considering extrinsic evidence about what the parties meant to agree to, if that evidence is not reflected within the agreement itself (Posner 2004).

${ }^{3}$ As compared, for example, with criminal statutes, in which parties generally have little discretion about whether they "engage" with the law. In contexts like these, legal realist perspectives tend to focus more on questions of legal consciousness-how people interpret the law and incorporate it into their everyday lives-and patterns of discretionary enforcement. 


\section{The Behavioral Force of Unenforceability}

First, contracting parties may enter into contracts that contain provisions they know, or suspect, are legally unenforceable. Though courts generally give parties significant latitude in determining what they may agree to in a contract, some provisions cannot be enforced for a variety of reasons, largely based on social policy considerations (Restatement $1981 \S 178$ ). Parties cannot, for instance, legally enforce a contract based on unlawful subject matter: courts will not enforce an agreement in which I agree to sell you heroin, or in which you agree to murder someone.

More conventionally, contracts often contain clauses that their authors know to be unenforceably overbroad. This arises commonly, but not exclusively, in contracts of adhesion (or "form contracts"), in which one party has more or less exclusive ability to specify the terms without negotiation. For instance, residential leases often contain clauses that are unenforceable under state landlord/tenant law; employment contracts frequently contain post-employment non-compete clauses, which are commonly executed despite the fact that state laws often make those clauses unenforceable (Sullivan 2009).

Why might sophisticated parties include clauses in their contracts that they know to be invalid? To do so seems illogical if one assumes that parties enter into agreements in full good faith, or if parties waste resources in attempting to enforce unenforceable agreements (Kostritsky 1988, Kuklin 1987, Sullivan 2009). Yet their inclusion persists.

The most reasonable interpretation as to why is that the party who chooses to include the clause assumes that the other party believes it to be valid, or at least will act as though it is. If I don't know that non-compete clauses are unenforceable under a given state statute, I am likely to follow its edicts anyway. In this way, unenforceable clauses are performative: they "work" functionally, even though they don't "work" legally. In a sense, then, these clauses work because of chilling effects-because of uncertainty and imperfect knowledge, they deter conduct beyond that which is actually legally proscribed.

The inclusion of unenforceable clauses in contracts of adhesion may strike us as unfair to the unsavvy contracting party, whose lack of sophisticated legal knowledge operates as a barrier to her rights, and operates to ascribe ever more influence to the more powerful contracting party (cf. Galanter 1974). But instances of this phenomenon exist as well that would likely strike us as less problematic, and even socially beneficial.

Sometimes, parties might include terms that they know to be unenforceable in order to express prosocial norms for future behavior (Van Der Burg 2001). Consider, for example, Gould's (2001) study of college hate speech codes. In the 1990s, many American universities retained or enacted codes-proscriptions on demeaning speech, harassment, and the like-that were clearly unconstitutional given recent well-publicized Supreme Court holdings on the First Amendment. Gould explores why these sophisticated institutions failed to comply with unambiguous legal precedent, and in fact, sometimes made decisions in direct contravention thereof. A key reason is that the speech codes carried symbolic and communicative weight, even if they lacked legal force; they acted to symbolize schools' commitment to particular values and to articulate a policy position. We can easily imagine contracting parties behaving according to similar motivations. 
In other cases, unenforceable clauses are included even when the parties are on a fairly even playing field in terms of resources and knowledge. In these cases, the inclusion of an unenforceable contract term can serve both parties' interests, by operating to influence and communicate norms for each of their future behavior. Consider, for example, the inclusion of "infidelity clauses" in prenuptial and postnuptial agreements, which contractually bind spouses to a (usually financial) consequence if they cheat; these clauses are sometimes colloquially referred to as "pay if you stray" clauses. Many courts refuse to enforce these clauses on public policy grounds-courts often are loath to inquire into issues of fault in divorce cases, and these terms edge up to such an inquiry-yet these and other so-called "lifestyle clauses" are often included anyway, even when family lawyers (who should know better about their unenforceability) are involved (Marsh 2013). Yet, these clauses are still socially functional: they serve to communicate expectations between contracting parties, and even if legally unenforceable may act to precommit behavior in a socially desirable way (DeLong 2013).

To sum up: parties knowingly include unenforceable terms in contracts in order to set expectations for one another's future behavior-including behavior that is legally beyond the reach of the formal contract. Though this effect of contracting may serve to intensify power asymmetries in some cases, it might also be used to prosocial effect, to mutually precommit behavior, or to express allegiance to certain norms and values.

\section{Vagueness and Long-term Relationships}

A second set of contracting practices involves the inclusion of terms that, while not facially unenforceable in the manner we have discussed above, are purposefully vague. Terms might be left uncertain for a variety of reasons. It might be unduly cumbersome to prespecify terms if the context of the agreement is likely to shift; parties may have a variety of motivations for conducting some aspects of their business "unofficially" (i.e., in ways that are not memorialized in a formal legal document); the pecuniary or social costs of negotiating terms might be great enough that parties would rather take a chance, based on their perceptions of costs and probability of the contract being breached, than expend resources delineating all terms up front (Posner 2004). As a legal matter, contracts are not enforceable if their material terms are left vague or open-ended; an "agreement to agree," though undertaken commonly in practice, lacks legal weight (Restatement 1981 §33).

The seminal sociolegal scholarship on this phenomenon is Stewart Macaulay's 1963 study about what he termed "non-contractual relations" in business. Macaulay interviewed businessmen (it was, indeed, all men at the time of his study) about how they went about negotiating transactions and enforcing agreements. He found that, to a surprising degree, his interviewees left many aspects of their contractual relationships vaguely planned, incompletely defined, or imperfectly resolved; in other words, few of the transactions in which these parties engaged were neatly rationalized in the way that contract exchange theory would portend. Importantly, this was not for lack of sophistication among the parties; in fact, it seemed to be a 
deliberately undertaken and widespread practice in spite of the parties' "knowing better," even when significant financial risks were on the line.

Why might parties act in such a way? In part, Macaulay's businessmen were unworried about the eventual enforceability of a contract in court because alternative mechanisms, like reputation and internal sanctions (formal or informal), served in its place (more on this in the next section). Most significantly, parties may choose not to insist on a perfect "meeting of the minds" on every term because they anticipate (and hope) that their relationship will extend beyond the contract at immediate issue. Being exacting and formal about each and every aspect of an agreement might endanger the long-term relationship of the parties. As Macaulay puts it, "[d]etailed negotiated contracts can get in the way of creating good exchange relationships[.] ... If one side insists on a detailed plan, there will be delay while letters are exchanged as the parties try to agree on what should happen if a remote and unlikely contingency occurs. In some cases they may not be able to agree at all on such matters and as a result a sale may be lost" (p. 64). Further, he suggests that in carefully negotiated relationships, parties sometimes perform "only to the letter of the contract," and that such prespecification "indicates a lack of trust and blunts the demands of friendship, turning a cooperative venture into an antagonistic horse trade" (p. 64). As such, it can be both operationally and socially beneficial to leave some terms underspecified; vagueness preserves operational flexibility for parties to deal with newly arising circumstances after an agreement is made, and sets the stage for social stability in an ongoing relationship.

This way of understanding contracting behavior has been described as a relational theory of contract (Macneil 1978). Relationalism pays close attention to the interactions among norms, practices, and doctrines in transactions, as opposed to a more formalistic, classical theory of exchange that concentrates principally on legal decision rules. As described by Gordon (1985, p. 569):

In the "relational" view of Macaulay and Macneil, parties treat their contracts more like marriages than like one-night stands. Obligations grow out of the commitment that they have made to one another, and the conventions that the trading community establishes for such commitments; they are not frozen at the initial moment of commitment, but change as circumstances change; the object of contracting is not primarily to allocate risks, but to signify a commitment to cooperate.

The analogy to marriage is apt (Scott and Scott 1998). Anyone in a long-term personal relationship knows that one does oneself no favors by fighting every fight, seeking resolution on every disagreement, clarifying every expectation, and adjudicating every breached promise. In many cases, the best way to preserve long-term stability in a relationship is to "take some hits" along the way, assuming that any immediately resulting unfairness will more or less shake out over time. The same intuition applies to contractual relations: by leaving some contractual obligations imprecisely detailed or defined, Macaulay's businessmen facilitated long-term outcomes that were better for both parties.

The particulars of Macaulay's landmark study, conducted in the 1960s, might not hold as 
true today as they did then. The proliferation of form contracts, the explosion of legal departments in firms, and changing practice norms likely imply that business-to-business contracts are more carefully negotiated now than they were in the past, undercutting some of the dynamics Macaulay observed. That said, Macaulay's study spawned a legacy of empirical research documenting how thoroughly social and relational considerations underlie transactions, in one form or another, and among all sorts of party relations (on this point, see generally Zelizer 2007) - to the point that Macaulay, in reviewing some of this research, later described contracts as "at best, stand[ing] at the margin of important long-term continuing business relations" (Macaulay 1985, p. 467). Even when specific circumstances change, this line of research suggests that relational considerations remain fundamental to understanding how contracts and contracting practices operate.

\section{Strategic Nonenforcement and the Shadow of the Law}

A third set of contracting behaviors entails parties' decisions not to pursue enforcement of agreements that are facially enforceable. Legal obligations of all types often go unenforced. Often, parties' lack of resources or awareness may limit them from pursuing others' legal obligations in court (Felstiner et al. 1980). But in other cases, failure to pursue a legal remedy serves social purposes for the non-enforcer, and may be part of a considered behavioral strategy. A good deal of sociolegal scholarship considers how individuals use law-and nonenforcement specificallyas a strategic resource for the management of their institutional and interpersonal relationships.

This dynamic is often called "bargaining in the shadow of the law" (Mnookin and Kornhauser 1979; Cooter et al., 1982). The basic premise is that formal enforcement-"taking someone to court" - is only one way in which people choose to enforce their legal obligations to one another, and is often not the best way. In part, this is due to the high costs of formal adjudication, in terms of both time and money (more on this later). Even when not formally used, the specter of the court has important effects, because it provides a backdrop and framework against which parties make bargains among themselves. And self-constructed bargains can, in some cases, be mutually advantageous: they avoid the "all-or-nothing" consequences that are likely to attend litigation in favor of more granular negotiations, can save time and money, and may be more cooperative in nature. Mnookin and Kornhauser's study considers such private ordering in the context of divorce agreements, and finds that the existence of legal rules-even if not formally appealed to for enforcement-very commonly enables parties to work out solutions regarding things like custody and child support "on their own." The calculus about whether to take someone to court depended on considerations like the degree of uncertainty, spiteful motivations, preferences for risk, and other variables; courts were also invoked as a means to "call someone's bluff" if negotiations broke down. Similarly, Merry (1979) found in her study of disputes in a poor neighborhood that the threat of formal adjudication in court influenced people's behavior, and could operate to bestow bargaining chips to less powerful members of the community (like women and the elderly). 
Bargaining in the shadow of the law may be differentially effective in different contexts of exchange. It tends to be a greater resource when strong community norms or networks provide viable alternative forms of sanction (Ellickson 1991; Macaulay 1963; Merry 1979; Charny 1990). For instance, if I am concerned about my reputation for fair dealing in a given community, if the community provides alternative forms of signaling (say, ratings on a website, or gossip in a small town), then resort to a lawsuit may be an unnecessary (and costly) way to enforce contractual obligations. For instance, Merry (1979) found that people resorted to formal adjudication less frequently in communities in which social networks were durable and wellbounded, because they preferred to use more informal dispute management techniques (recalling the long-term relationships among Macaulay's businessmen). Even appeals to morality and personal conscience may be effective extralegal means of enforcement (Wilkinson-Ryan and Baron 2009).

Enforceable contractual obligations, rather than operating as steadfast if-then consequences of noncompliance, create a backdrop of social expectations against which extralegal negotiations can occur. Nonenforcement, then, can be as much a "use" of contract as is enforcement.

\section{Smart Contracts Aren't So Smart}

Contracts are deeply social tools as well as legal ones. We have traced three contracting practices that reveal some of their social complexity and shed light on some of the mechanisms through which contracts actually "work." Together, these three practices (which are, of course, far from exhaustive) demonstrate how contracts operate as social resources, through and against which people manage their relationships, and within which legal obligations and social expectations are intricately interwoven and mutually constitutive.

What are the implications for blockchain-based contracts? I assert that "smart" contracts fail to take the social complexities of contracting into account; indeed, they are not designed to. We might think of smart contracts as book-smart, not street-smart: while they may facilitate technically perfect and seamless implementation of agreements, and lower transaction costs, they fail to understand or integrate the social world. The social friction required to negotiate and enforce a "dumb" contract can be highly functional-by preserving flexibility, facilitating stability, signaling community norms, and the like. Blockchain-based contracts rely on careful prespecification of terms and automated enforcement of obligations. These contracts thus impose a degree of inflexibility on contractors' relations that might short-circuit a number of alternative uses to which law is put. Smart contract boosterism demonstrates the appeal of bright-line enforcement rules. Rules of this sort often garner strong support from the tech community due to their computability and perceived efficiency. But when these rules hit the ground of real practice, custom, and human behavior, their effects may be nonobvious, even counterintuitive (Rose 1988).

Notably, the social effects of contract-which do not require recourse to courts for enforcement-represent a form of self-execution, as well, though a different sort than that contemplated by smart contract proponents. We might think of contracts as sometimes having 
the capacity to socially self-execute-they "work" via their effects on parties' behavior, even without formal adjudication-rather than through technical self-execution, in which enforcement relies on code. Social self-execution relies on the communicative functions contracting serves between parties, which may be wholly distinct from their formal legal effect. In a sense, then, contracts speak in multiple registers at once, to multiple audiences-a form of what Dan-Cohen (1984, p. 630) termed "acoustic separation." Dan-Cohen posited that "the law necessarily contains two sets of messages. One set is directed at the general public and provides guidelines for conduct. ... The other set of messages is directed at [legal] officials and provides guidelines for their decisions." Automated contracts tend to focus on contracts' capacity for legal communication, perhaps to the expense of their social capacity.

Of course, this isn't to say that there is no role for automated contracts, nor that such contracts might introduce some desirable social consequences with respect to equitable access to justice. As we have discussed, a good deal of nonenforcement of contractual obligations results from the high transaction costs of taking someone to court. To the extent that smart contracts would reduce these transaction costs, they might beneficially remove an impediment to lessresourced parties' contractual rights. At the same time, automated enforcement of contractual obligations-particularly when such obligations are instantiated via interconnected objectsseems likely to have detrimental effects on underresourced people, who often depend on (even asymmetric) transaction costs to grant them a "buffer" within which to operate. Consider, for example, several recent cases in which subprime lenders have used starter interruptor devices to remotely, and immediately, disable vehicles whenever a borrower falls behind on payments (Corkery and Silver-Greenberg 2014; Jeong 2016; Segal 2016), to the great detriment of borrowers.

As a policy matter, then, we ought to think carefully about the features of the social setting in which smart contracts are permitted to operate, the degree to which they might preclude other means of enforcing obligations, and the social and normative implications of this foreclosure. To be sure, the subject of the agreement is one consideration here: a stock trade, for instance, is likely to be a better candidate for smart contracting than performance of a personal service, due in part to the computational verifiability of events surrounding the exchange (though even contracts for financial products can be complex and may best be left willfully incomplete, as Levine (2016) points out). To realize their promise while mitigating against their potential disadvantages, ensuing discussion, development, and perhaps even regulation of smart contracts ought to attend explicitly to the relational contexts in which such contracts are deployed.

The foregoing discussion suggests that alternative enforcement mechanisms might work best when certain social resources are present in the contracting relationship that can be drawn upon by the parties. For instance, are the parties likely to want to engage in continued relations beyond the immediate agreement, suggesting that reputation and stability might be desirable alternatives to automated enforcement and strict prespecification of terms? Are the parties motivated to preserve flexibility in their contract, to account for a changing environment, or to reduce the transaction costs of meeting an initial agreement? Are they chiefly trying to communicate particular precommitments or behavioral norms to one another by way of contracting? Do they trust one another? Are they part of the same community, and if so, how 
durable are relationships in that community? Do alternative forms of signaling (ratings, custom, reputational signals, gossip) exist to incentivize behavior? Questions like these will help us to understand the social contexts in which contracts are likely to "work" in a certain way, and how technological interventions might operate if deployed there.

\section{Acknowledgments}

The author gratefully acknowledges James Grimmelmann, Arvind Narayanan, Matt Salganik, Vasilis Kostakis, Primavera De Filippi, and Diego Gonzalez-Rodriguez for helpful feedback on prior iterations of this paper.

\section{Author Biography}

Karen Levy is an assistant professor of Information Science at Cornell University and associated faculty at Cornell Law School. Dr. Levy researches how law and technology interact to regulate social life, with particular focus on social and organizational aspects of surveillance. Much of her research analyzes the use of monitoring for social control in various contexts, from long-haul trucking to intimate relationships. She is also interested in how data collection uniquely impacts, and is contested by, marginalized people. Dr. Levy holds a Ph.D. in Sociology from Princeton University and a J.D. from Indiana University Maurer School of Law.

\section{References}

Casey, M. 2016. “Could Blockchain Technology Help the World's Poor?” World Economic Forum Agenda, March 9. Accessed 10 June 2016.

https: / / www.weforum.org/agenda/2016/03/ could-blockchain-technology-help-theworlds-poor.

Cassano, J. 2014. "What are Smart Contracts? Cryptocurrency's Killer App." Fast Company, September 17. Accessed 10 June 2016. http://www.fastcolabs.com/3035723/appeconomy/smart-contracts-could-be-cryptocurrencys-killer-app.

Charny, D. 1990. "Nonlegal Sanctions in Commercial Relationships." Harvard Law Review 104(2): 373-467.

Cooter, R., S. Marks, and R. Mnookin. 1982. "Bargaining in the Shadow of the Law: A Testable Model of Strategic Behavior." Journal of Legal Studies 11(2): 225-251.

Corkery, M. and J. Silver-Greenberg. 2014. "Miss a Payment? Good Luck Moving That Car." New York Times, September 24. Accessed 7 June 2016. http:/ / dealbook.nytimes.com/2014/09/24/miss-a-payment-good-luck-moving-that$\mathrm{car} /$.

Dan-Cohen, Meir. 1984. “Decision Rules and Conduct Rules: On Acoustic Separation in Criminal Law." Harvard Law Review 97(3): 625-677. 
DeLong, S. 2013. "Acoustic Separation and Use of Unenforceable Contracts in Intimate Relationships." Talk delivered at 2013 Annual Meeting of Law and Society Association (Boston, MA).

Economist. 2015. "The Trust Machine." October 31. Accessed 10 June 2016. http:/ / www.economist.com/news/leaders/21677198-technology-behind-bitcoin-couldtransform-how-economy-works-trust-machine.

Economist. 2016. "Theft is property." June 25. Accessed 11 November 2016. http:/ / www.economist.com/news/ finance-and-economics/21701136-cyber-attackeroutsmarts-smart-contract-theft-property.

Ellickson, R. C. 1991. Order Without Law: How Neighbors Settle Disputes. Cambridge: Harvard University Press.

EtherScripter blog. n.d. "What is Ethereum?" Accessed 10 June 2016. http:/ / etherscripter.com/what_is_ethereum.html.

Felstiner, W. L., R. L. Abel, and A. Sarat. 1980. "The Emergence and Transformation of Disputes: Naming, Blaming, Claiming..." Law and Society Review 15: 631-654.

Galanter, M. 1974. "Why the 'Haves' Come Out Ahead." Law and Society Review 9(1): 95-160.

Gordon, R. W. 1985. "Macaulay, Macneil, and the Discovery of Solidarity and Power in Contract Law." Wisconsin Law Review 1985(3): 565-579.

Gould, J. B. 2001. “The Precedent That Wasn't: College Hate Speech Codes and the Two Faces of Legal Compliance." Law and Society Review 35(2): 345-392.

Grimmelmann, J. and A. Narayanan. 2016. "The Blockchain Gang." Slate, February 16. Accessed 6 June 2016.

http:/ / www.slate.com/articles/technology/future_tense/2016/02/bitcoin_s_blockchai n_technology_won_t_change_everything.html.

Jeong, S. 2016. “How Technology Helps Creditors Control Debtors.” The Atlantic, April 15. Accessed 7 June 2016.

http:/ / www.theatlantic.com/technology/archive/2016/04/ rental-companycontrol / 478365/.

Kostritsky, J. P. 1988. "Illegal Contracts and Efficient Deterrence: A Study in Modern Contract Theory." Iowa Law Review 74(1): 115-163.

Kuklin, B. 1987. "On the Knowing Inclusion of Unenforceable Contract and Lease Terms." University of Cincinnati Law Review 56: 845-918.

Levine, M. 2016. "Basic Income and Blockchain Courts." Bloomberg View, May 5. Accessed 5 December 2016. https:// www.bloomberg.com/view/articles/2016-05-05/basic-incomeand-blockchain-courts.

Macaulay, S. 1963. "Non-Contractual Relations in Business: A Preliminary Study." American Sociological Review 28: 55-67.

Macaulay, S. 1985. “An Empirical View of Contract.” Wisconsin Law Review 1985(3): 465-482.

MacKenzie, D. 2008. An Engine, Not a Camera: How Financial Models Shape Markets. Cambridge: MIT Press. 
Macneil, I. R. 1978. “Contracts: Adjustment of Long-Term Economic Relations Under Classical, Neoclassical, and Relational Contract Law." Northwestern Law Review 72(6): 854-905.

Marsh, L. 2013. "Lifestyle Prenups, Like the Deal Between Jessica Biel and Justin Timberlake, Are A Hot Trend." New York Daily News, June 4. Accessed 9 June 2016. http:/ / www.nydailynews.com/life-style/ deal-violation-part-lifestyle-prenups-article1.1361889 .

Maurer, B., T. C. Nelms, and L. Swartz. 2013. “'When Perhaps the Real Problem is Money Itself!': The Practical Materiality of Bitcoin." Social Semiotics 23(2): 261-277.

Merry, S. E. 1979. "Going to Court: Strategies of Dispute Management in an American Urban Neighborhood." Law and Society Review 13: 891-925.

Mertz, E. 1999. "Tapping the Promise of Relational Contract Theory: Real Legal Language and a New Legal Realism." Northwestern Law Review 94: 909-936.

Mnookin, R. H., and L. Kornhauser. 1979. "Bargaining in the Shadow of the Law: The Case of Divorce." Yale Law Journal 88(5): 950-997.

Narayanan, A. 2015. "The Future of Bitcoin?" YouTube, April 27. Accessed 6 June 2016. https: / / youtu.be/YG710XPtzD4.

Peck, M. 2016. “'Hard Fork' Coming to Restore Ethereum Funds to Investors of Hacked DAO.” IEEE Spectrum, July 19. Accessed 5 December 2016. http://spectrum.iee.org/techtalk/ computing/networks/ hacked-blockchain-fund-the-dao-chooses-a-hard-fork-toredistribute-funds.

Posner, R. A. 2004. "The Law and Economics of Contract Interpretation." Texas Law Review 83: 1581-1614.

Raskin, M. Forthcoming. "The Law of Smart Contracts." Georgetown Law Technology Review. Available at https: / / papers.ssrn.com/sol3/ papers.cfm?abstract_id=2842258.

Restatement ( $2^{\text {nad }}$ of Contracts. 1981.

Riles, A. 2011. Collateral Knowledge: Legal Reason in the Global Financial Markets. Chicago: University of Chicago Press.

Rose, C. M. 1988. "Crystals and Mud in Property Law." Stanford Law Review 40: 577-610.

Scholz, L. H. Forthcoming. "Algorithmic Contracts." Stanford Technology Law Review. Available at http:/ / papers.ssrn.com/sol3/ papers.cfm?abstract_id=2747701.

Scott, E. S., and R. E. Scott. 1998. "Marriage as Relational Contract." Virginia Law Review 84(7): 1225-1334.

Segal, D. 2016. "Hauling a Load of Breakdowns and Broken Hearts." New York Times, April 30. Accessed 7 June 2016. http://www.nytimes.com/2016/05/01/your-money/hauling-aload-of-breakdowns-and-broken-hearts.html.

Sullivan, C. A. 2009. “The Puzzling Persistence of Unenforceable Contract Terms." The Ohio State Law Journal 70(5): 1127-1177.

Tapscott, D., and A. Tapscott. 2016. "The Impact of the Blockchain Goes Beyond Financial Services." Harvard Business Review, May 10. Available at https://hbr.org/2016/05/theimpact-of-the-blockchain-goes-beyond-financial-services. 
Van Der Burg, W. 2001. “The Expressive and Communicative Functions of Law, Especially With Regard to Moral Issues." Law and Philosophy 20(1): 31-59.

Wilkinson-Ryan, T. and J. Baron. 2009. "Moral Judgment and Moral Heuristics in Breach of Contract." Journal of Empirical Legal Studies 6: 405-423.

Wright, A., and P. De Filippi. 2015. "Decentralized Blockchain Technology and the Rise of Lex Cryptographia." Available at http:// papers.ssrn.com/sol3/ papers.cfm?abstract_id=2580664.

Zelizer, V. "Pasts and Futures of Economic Sociology." American Behavioral Scientist 50: 1056-1069. 